This is the peer reviewed version of the following article: Holloway, J.V., Rillig, M.C., Gurnell, A.M. 201. Physical Environmental Controls on Riparian Root Profiles associated with Black Poplar (Populus Nigra L.) along the Tagliamento River, Italy. Earth Surface Processes and Landforms, early view, which has been published in final form at DOI: 10.1002/esp.4076. This article may be used for non-commercial purposes in accordance with Wiley Terms and Conditions for SelfArchiving

\title{
Physical Environmental Controls on Riparian Root Profiles associated with Black Poplar (Populus Nigra L.) along the Tagliamento River, Italy
}

\author{
James V. Holloway ${ }^{1}$, Matthias C. Rillig ${ }^{2,3}$, Angela M. Gurnell ${ }^{1}$ \\ 1 Queen Mary University of London, School of Geography, Mile End Road, London E1 4NS, United \\ Kingdom \\ 2 Freie Universität Berlin, Institut für Biologie, Plant Ecology, Altensteinstr. 6, Berlin D-14195, \\ Germany \\ 3 Berlin-Brandenburg Institute of Advanced Biodiversity Research (BBIB), Berlin D-14195, Germany
}

\begin{abstract}
Tree roots contribute to the resistance of riparian sediments to physical deformation and disintegration. Understanding reinforcement by roots requires information on root distributions within riparian soils and sediments. Continuous-depth models or curves have been proposed to describe vertical root density variations, providing useful indicators of the types of function that may be appropriate to riparian trees, but have generally been estimated for terrestrial species or broad vegetation types rather than riparian species or environments.
\end{abstract}

We investigated vertical distributions of roots $>0.1 \mathrm{~mm}$ diameter of a single riparian tree species (Populus nigra L.) along the middle reaches of a single river (Tagliamento river, Italy), where $P$. nigra dominates the riparian woodland. Root density (hundreds. $\mathrm{m}^{-2}$ ) and root area ratio (RAR in $\mathrm{cm}^{2} . \mathrm{m}^{-2}$ ) were measured within $10 \mathrm{~cm}$ depth increments of 24 excavated bank profiles across 9 sites. Sediment samples, extracted from distinct strata within the profiles, were analysed for moisture content, organic matter content and particle size. Statistical analyses identified two groups of wetter and drier profiles and five sediment types.

Following $\log _{\mathrm{e}}$-transformation of root density and RAR, linear regression analysis explored their variation with depth and, using dummy variables, any additional influence of moisture and sediment type. Significant linear regression relationships were estimated between both root density and RAR and depth which explained only $15 \%$ and $8 \%$ of the variance in the data. Incorporating moisture and then sediment characteristics into the analysis increased the variance explained in root density to $29 \%$ and $36 \%$ and in RAR to $14 \%$ and $26 \%$.

We conclude that riparian tree root density and RAR are highly spatially variable and are poorly explained by depth alone. Complex riparian sedimentary structures and moisture conditions are important influences on root distributions and so need to be incorporated into assessments of the contribution of roots to river bank reinforcement.

\section{KEY WORDS}

Black poplar (Populus nigra L.), root density, root area ratio, riparian sediments, root profile

\section{INTRODUCTION}

The root architecture of riparian tree species varies widely, being comprised of a mix of primary roots, which tend to be positively geotropic, secondary ones which tend to be diageotropic, and further branches that are mainly ageotropic, responding to water and nutrient demand and availability (Edmaier et al., 2011). There are particularly notable contrasts between taproot-dominated (e.g., Salix spp.) and more extensive suckering horizontal root systems, which have been interpreted as alternative adaptations of riparian plants for better anchorage on the bank face in comparison with the bank top and floodplain (Mallik and Rasid, 1993). Although a great diversity of rooting patterns exists, reflecting the heterogeneity of water and nutrient sources in the riparian substrate, perennial woody species generally display extensive lateral roots (Stromberg, 2013), presumably to secure a continuing 
supply of resources in this patchy environment. Nevertheless, there is significant plasticity in the development of perennial root systems, with facultative phreatophyty observed in response to the growing season precipitation regime and longer-term changes in the water table (Naumburg et al., 2005, Rood et al., 2011).

Tree roots are important contributors to the resistance of riparian sediments to physical deformation and disintegration. The mechanisms that contribute to this reinforcement effect are both direct (dependent on the strength of the roots), and indirect (dependent on other factors which are themselves dependent on roots).

Analogous to the steel bars in reinforced concrete, roots directly increase the stresses required to cause blocks of sediment to 'calve off' river banks, by traversing potential failure planes and tying sediment masses to one other (Abernethy and Rutherfurd, 2000). Consequently, considerable effort has been devoted to determining critical breaking stresses for roots of different diameters and species (Hathaway and Penny, 1975, Stokes and Mattheck, 1996, Watson and Marden, 2004, Bischetti et al., 2005, Tosi, 2007, De Baets et al., 2008), which shows that the finest roots are disproportionately strong, with some notable differences in strength-diameter relationships among species. Recently, the phenomenon of root 'pullout' and soil friction interactions have been considered, highlighting the importance of root branching (Docker and Hubble, 2008), root orientation and density in relation to the angle of the failure surface (Thomas and Pollen-Bankhead, 2010, Giadrossich et al., 2013), and the moisture status of the soil (Pollen, 2007).

At a smaller spatial scale and below the water surface, hydraulic erosion of riparian sediments is also directly affected by the presence of roots, with early experiments revealing that plant roots could reduce sediment erosion by up to 20,000 times (Smith, 1976). Gyssels et al. (2005) argue that the sediment erosion rate is exponentially related to root parameters, and comparative experiments have demonstrated that it is primarily fine roots, which have the highest surface area and tensile strength, that enmesh sediment particles and aggregates, and increase the shear stress required to detach them from the river bank or bed surface (Burylo et al., 2012). In addition to their physical binding effect, roots also increase surface hydraulic roughness, reducing boundary shear stress (Kean and Smith, 2004) and, in extremis, protection may constitute an almost continuous bank cover of tightly interwoven roots, effectively preventing any movement of water over the sediment surface beneath.

Roots also indirectly influence sediment strength or resistance to failure through impacts on friction and cohesion of the soil matrix relative to a root-free soil. Pore water affects both of these properties, but is constantly removed by vegetation to supply the process of transpiration, usually at a rate close to theoretical potential evapotranspiration in actively growing riparian forest (Tabacchi et al., 2000). The resulting reduction of pore water pressure and development of matric suction can reduce the risk of bank failure by a much greater degree than mechanical reinforcement (Simon and Collison, 2002, Pollen-Bankhead and Simon, 2010), but the effect is seasonal and frequently at its minimum in periods of vegetation dormancy in temperate environments, when bank failure risk is usually greatest.

Understanding river bank reinforcement by roots requires information on root distribution within riparian soils and sediments. A variety of continuous-depth models or curves have been proposed to describe vertical root density variations including inverse-square (Monteith et al., 1989), exponential (Gerwitz and Page, 1974), proportional exponential (fraction of entire root system, Jackson et al., 1996) and logistic (Schenk and Jackson, 2002). Although these provide useful indicators of the types of function that may be appropriate to riparian trees, they have been estimated for terrestrial species or broad vegetation types and so do not relate to specific riparian species or riparian environmental conditions. Therefore, establishing such distributions has been the main motivation for field investigations of riparian root system structure, including the distributions of root area ratio (sectional area of roots per unit sectional area of bank), root diameters (since breaking stress is dependent on size) and root density (frequency per unit area of bank section) through riparian sediments. With the exception of one study in which coarse roots of over $1 \mathrm{~cm}$ diameter were observed in eroding banks from a boat (Rood et al., 2011), another in which whole tree root systems were removed from man-made canal, dam and flood protection dikes (Vennetier et al., 2015, Zanetti et al., 2015), and two recent papers in which the coarse root architecture of eight individual mature Populus nigra trees was investigated and interpreted (Holloway et al 2016 a, b), riparian root investigations have been conducted using the wall-profile or 'trenching' method (Maeght et al., 2013), where exposed roots are investigated in excavated vertical sediment profiles. Some early excavations by Abernethy and Rutherfurd (2001) and Simon and Collison (2002) found a steep (near exponential) decline in root numbers with depth, although this only approached a steady curve at distances of several metres from the trunks of nearby trees, at which point numbers and area of roots became extremely low, and depth distributions of root area ratio varied dramatically with species and site.

The variability of soil moisture retention and water sources appears to be a major determinant of riparian root system structure. Root systems extending down tens of metres have been reported for drought-prone Australian systems (Hubble et al., 2010), and more typical values of maximum rooting depths of between 35 and $45 \%$ of tree height have been reported by Docker and Hubble (2008). Pollen et al. (2004) found large diameter roots to 
be more closely associated with particular areas of moisture availability than the fine root system, and asymmetries in large roots of the whole root systems removed from man-made dikes have been found to reflect asymmetries in soil moisture (Zanetti et al., 2015). An extensive meta-analysis by Stromberg (2013) highlights the fact that the root systems of riparian species are particularly well-adapted to reaching and utilising deep phreatophytic water sources, and also that maximum rooting depth is highly variable, reflecting both the climate to which riparian species are adapted and their growth form (shrubs being most deeply rooted). In their observations of river cutbanks, Rood et al. (2011) note that non-riparian species such as Picea glauca do not develop the deep roots observed in Populus spp. that allow permanent access to the capillary fringe. Rood et al. (2011) also identify associations between this deep phreatophytic root distribution and climatic moisture availability in the growth season, suggesting that when shallow (precipitation-related) water sources are reliable during critical seasons, there is less investment in deep roots. Stable isotope studies suggest, however, that riparian poplars are able to switch between deep and shallow water sources within and between years (Singer et al., 2014), implying that they maintain a well-developed system of roots both within surface layers and deeper deposits. Furthermore, glasshouse experiments on riparian species confirm that fine root investment is highly plastic and driven by both water availability and shoot photosynthetic demand (Snyder and Williams, 2007).

In summary, current knowledge of riparian tree root development is incomplete. As a result, a great deal of simplification and many assumptions about root system structure are incorporated in current understanding and modelling of sediment reinforcement. Research has highlighted the great importance of access to water in structuring riparian root systems, but there is a very large amount of variability in the root systems observed, and there is a need for more observations of root distributions and associated environmental conditions. The present paper attempts to provide such information, specifically focussing on one widely-occurring riparian tree species: Populus nigra L.. Complementary research on the architecture of the coarsest root components of individuals of this species is reported elsewhere (Holloway et al., $2016 \mathrm{a}, \mathrm{b}$ ), whereas the present paper employs the trenching method to explore root profiles more generally to answer the following research questions:

1. Is there an association between riparian tree root properties and depth within the bank profile?

2. Does the association between root properties and depth within the bank profile vary with moisture availability?

3. Is there an association between root properties and properties of the surrounding sediment?

\section{METHODS}

\section{Field Methods}

Root and sediment profiles were investigated at three main locations (A, B, C) along $40 \mathrm{~km}$ of the middle to lower Tagliamento river, NE Italy, where the riparian woodland is dominated by P. nigra (Figure 1). These locations covered an altitudinal range of $140 \mathrm{~m}$ and a latitudinal range of 0.3 degrees. At each location, three separate sites with eroding river banks were investigated. At the first site at each location (A1, B1, C1), four replicate bank profiles were excavated, and at the remaining sites (A2, A3, B2, B3, C2, C3), two replicate bank profiles were excavated. Thus information was collected for 24 bank profiles in total.

A bank-top datum was established as a reference for all local bank profile measurements. The bank face was prepared by trimming long protruding roots and removing other debris that prevented access, and then the bank face was excavated back at least $0.2 \mathrm{~m}$ from its initial position to create a flat vertical bank profile approximately $0.5 \mathrm{~m}$ wide.

The diameter of all roots $>0.1 \mathrm{~mm}$ diameter that intersected the bank face within a $0.2 \mathrm{~m}$ wide vertical transect at the centre of the excavated profile were measured using digital callipers. These measurements were recorded within $0.1 \mathrm{~m}$ depth intervals below the bank top datum. For 22 bank profiles, measurements were taken at $0.1 \mathrm{~m}$ intervals from the bank top to the bank toe, in many cases excavating below the toe to the ambient water table level. However, at B2, only the lower part of the two profiles could be investigated because an accumulation of woody and other organic material was embedded in the upper part of the bank profile, making it impossible to establish a stable vertical profile or to fully distinguish the contained roots. The root diameter measurements were used to calculate root density (number of roots per unit area of bank face) and root area ratio (total cross sectional area of roots per unit area of bank face) for each $0.1 \mathrm{~m}$ depth interval down the bank profiles.

The sampled bank face was then re-cleaned and the positions $( \pm 5 \mathrm{~mm})$ of the boundaries of the major sedimentary layers within the bank were recorded. Sediment samples were extracted from at least $0.15 \mathrm{~m}$ horizontal depths into the exposed bank face from each layer. Samples of between 10 and $500 \mathrm{~g}$ (at least $10 \mathrm{~g}$ of the $<2 \mathrm{~mm}$ fraction) were collected with a $70 \mathrm{~mm}$ diameter riverside auger (Van Walt, UK) in finer sediments or a trowel in coarser sediments and thin strata. The samples were sealed immediately in polyethylene bags, and were subsequently 
transported to the laboratory where their gravimetric water content, particle size distribution and organic matter content were determined (methods described below).

Because these field procedures were undertaken on a number of different dates during the summer of 2013, an additional rapid sampling of sediments from all previously-sampled river bank locations (apart from B2, which had been deeply buried by flood-deposited sediments) was undertaken for comparative soil moisture characterisation on 2 August 2014. This followed a dry period with a month of continuous low flows monitored at a flow gauging station immediately downstream of site B. At each location, approximately $100 \mathrm{~g}$ sediment samples were taken from as close to the 2013 sampled bank profiles as was possible, and at $0.5,0.75$ and $1.0 \mathrm{~m}$ depth below the bank top. These samples were sealed immediately in polyethylene bags and were again assayed gravimetrically.

\section{Laboratory Methods}

Sediment water content was determined within 6 hours of field collection. The mass of the samples was measured to $+/-10 \mathrm{mg}$. Samples were then dried at $105^{\circ} \mathrm{C}$ until they reached stable mass and then sediment water content was calculated as the sediment mass lost during drying as a proportion of undried mass.

The size distribution of $>1 \mathrm{~mm}$ calibre fractions of sediment samples was determined by dry sieving. Sub-mm fractions were analysed on a Beckman Coulter LS 13320 Laser Diffraction Particle Size Analyzer. The coarsest sieve grade used was $8 \mathrm{~mm}$, and below $4 \mathrm{~mm}$, meshes at half-phi intervals were used (i.e., 8.0, 4.0, 2.8, 2.0, 1.4 and $1.0 \mathrm{~mm}$ ). Organic matter was digested in $30 \%$ hydrogen peroxide at $85{ }^{\circ} \mathrm{C}$ from duplicate $3 \mathrm{~g}$ subsamples of the $<1 \mathrm{~mm}$ sediment fractions before laser diffraction analysis. All subsamples were then agitated overnight on a rotary shaker in $30 \mathrm{ml}$ of dispersal agent $\left(50 \mathrm{~g} . \mathrm{L}^{-1}\right.$ sodium hexametaphosphate plus $7 \mathrm{~g} . \mathrm{L}^{-1}$ anhydrous sodium carbonate) and approximately $10 \mathrm{ml}$ of each of these treated subsamples was extracted by pipette and loaded into the laser sizer's auto-sampler. Final sample size class data were derived as the means of 4 runs. Laser diffraction analysis and sieving data were compiled into a single particle size distribution from which summary properties were estimated using the GRADISTAT software of Blott and Pye (2001).

\section{Data Analysis}

To address research question 1 and following previous work by other researchers on the idealised distribution of tree roots with depth, relationships between the $0.1 \mathrm{~m}$ depth interval midpoint and root density (number of roots per unit area) and root area ratio (total root area per bank section area) in each depth interval were explored using linear regression analysis. Linear regression models were estimated from the raw, squared and logarithmically transformed root data (dependent variables) and both depth alone and also depth and depth ${ }^{2}$ (independent variables). However, as maximum rooting depth was not reached, despite extending excavated bank profiles to the water table in many cases, the logistic dose-response curve used by Schenk and Jackson (2002) could not be tested.

To address research question 2, the investigated bank profiles were split into two groups based upon their moisture content. Both the 2013 and 2014 estimates of sediment moisture content were used for this purpose, and statistically significant groups were identified using Kruskal Wallis tests with multiple pairwise comparisons based on Dunn's procedure. The above-described regression analyses were then repeated, but on this occasion a dummy variable and its interaction with depth (and where appropriate, depth ${ }^{2}$ ) were included to indicate moisture conditions, and thus to identify whether relationships between root variables and depth differed according to moisture conditions at the sampled sites.

To address research question 3, eight sediment properties were explored using both Principal Components Analysis (PCA) applied to a rank correlation matrix and Hierarchical Cluster Analysis (HCA). The sediment properties were the $\%$ organic material, the mean, median $\left(D_{50}\right), 90^{\text {th }}$ percentile $\left(D_{90}\right)$ and sorting index extracted from the mineral particle size distribution and expressed in $\Phi$ units, and the $\%$ gravel, $\%$ sand and $\%$ silt + clay content of the mineral particles. In the HCA, Euclidean distance and Ward's algorithm were used to produce and interpret a classification of the sampled riparian sediments. The degree to which root properties varied according to the sediment class in which they were found was then explored using Kruskal Wallis tests with multiple pairwise comparisons based on Dunn's procedure. In this analysis, in addition to considering the two root properties (density and RAR) determined for all measured roots (i.e. all roots $>0.1 \mathrm{~mm}$ diameter), median root diameter was also considered. In addition, the measured roots were also split into fine (i.e. roots $<0.5 \mathrm{~mm}$ diameter) and coarse (i.e. $>0.5 \mathrm{~mm}$ diameter) roots so that their density, RAR and median diameter could be considered separately. Although arbitrary, the $0.5 \mathrm{~mm}$ diameter threshold between fine and coarse roots is at the smaller end used in other studies of tree roots (Block et al., 2006) and, in the present study, it aided exploration 
of whether the distribution of finer roots that predominantly absorb water and nutrients differs from that of coarser roots that predominantly perform transport and mechanical support functions across the sediment types encountered at the studied sites.

Finally, the combined explanatory power of depth, moisture and sediment was explored using multiple regression analysis. Dummy variables were assigned to the five sediment classes so that their contribution to determining root density and RAR could be investigated at wetter and drier sites and with depth. Stepwise multiple regression analysis was used to select the best subset of each of the dummy variables, their interactions with one another (i.e. interactions between each sediment class and the moisture class of the profile in which they were located), and their individual and joint interactions with depth, in explaining $\log _{\mathrm{e}}$-transformed root density and RAR. The selected regression model was the one that had the highest $\mathrm{R}^{2}$ (adjusted for degrees of freedom) and had intercept and slope coefficients that were all statistically significant $(\mathrm{p}<0.05)$.

\section{RESULTS}

The number of bank profiles, depth range and number of depth intervals (total 365) investigated for root characteristics in 2013 are summarised in Table 1. In addition during 2013, 185 sediment samples were extracted from the centre of sedimentary strata exposed in the excavated bank profiles, from which moisture and organic content were determined and also the particle size distribution of the mineral sediment. A further 48 sediment samples were obtained on 2 August 2014 (2 samples at each of $0.5,1.0$ and $1.5 \mathrm{~m}$ from the bank top at sites A1, A2, A3, B1, B3, C1, C2, C3) to determine near-simultaneous moisture content of sediments at the investigated sites.

\section{Sediment Properties}

The 185 sediment samples obtained during 2013 varied widely in calibre from mainly gravel (96.7\%) to predominantly silt and clay (86.4\%) with organic matter content varying between 0.05 and $7.93 \%$ (Table 2 ). To produce estimates of sediment properties for the $10 \mathrm{~cm}$ depth increments over which root properties were counted, the proportion of each $10 \mathrm{~cm}$ depth increment attributable to each sediment layer was calculated and weighted averages for all overlapping sediment layers were assigned to each $10 \mathrm{~cm}$ depth increment according to their proportional overlap. For 15 of the $10 \mathrm{~cm}$ intervals, no overlapping sediments were sampled. Estimated values for eight sediment properties (Table 2) for the remaining 350 depth intervals were subjected to both a Principal Components Analysis (PCA) and Hierarchical Cluster Analysis (HCA) to develop and interpret a classification of the broad sediment types that were present in the excavated bank profiles.

PCA was applied to a Spearman's rank correlation matrix rather than a product moment correlation matrix because of the non-normality of the data set. The first two components explained over $91 \%$ of the variability in the data set (Table 3). The first component explained over $79 \%$ of the variability and had a high negative loading on $\%$ Gravel and high positive loadings on sorting, \% Organic, \% Silt+clay and the mean, $\mathrm{D}_{50}$ and $\mathrm{D}_{90}$ particle sizes (in $\Phi$ units), implying a gradient from coarse, well sorted (negative) to fine, more organic, poorly sorted (positive) sediments. The second component explained an additional $12 \%$ of the variability in the data set and had a high positive loading on $\%$ Sand.

HCA applied to the same data set used Euclidean distance and Ward's clustering algorithm to identify five clear and interpretable sediment classes. Ward's method was selected because it identified a few relatively even-sized, interpretable classes. The data were not standardised prior to clustering but the percentage data ( $\%$ Gravel, $\%$ Sand, \% Silt+clay and \% Organic) were expressed as proportions of 1 to prevent them having an over-riding influence on cluster discrimination. Five classes were selected to represent the data based on a change in slope on the agglomeration schedule plot, which indicated that 4 to 6 classes summarised the data well, and the cluster dendrogram, which indicated that 5 classes gave a reasonably even subdivision of the data set among the classes. The eight sediment properties of the centroids of these five classes are listed in Table 4. These illustrate that class 1 is mainly gravel, class 2 has a high gravel content but also a sizeable proportion of sand, and class 3 is a gravelsand mix but also contains a sizeable quantity of silt and clay. Sediments in classes 1 to 3 contain negligible organic material. Class 4 is predominantly sand whereas class 5 is predominantly silt and clay. Both classes 4 and 5 contain a small amount of organic material. Kruskal Wallis tests followed by multiple pairwise comparisons using Dunn's procedure within Bonferroni correction revealed that all of the five sediment classes were significantly different from one another in relation to at least one of the eight sediment properties.

When a scatter plot of the scores of the 350 samples on principal components 1 and 2 is coded according to the five sediment classes, the classes show distinct, discrete distributions with respect to the sediment-size related PC gradients (Figure 2). 
The moisture content of the sediments sampled in both 2013 and 2014 was also investigated. Both these data sets showed distinct differences in moisture content between the studied sites (Figure 3). Because the variance in moisture content differed between the sampled sites, nonparametric Kruskal Wallis tests were applied to both the 2013 and 2014 data sets to assess whether the sites showed statistically significant differences in their moisture content. There were significant differences in moisture content determined from 2013 samples between sites (K $=202.2, \mathrm{p}<0.0001$, degrees of freedom $=8 ; 2014: \mathrm{K}=28.7, \mathrm{p}<0.001$, degrees of freedom $=7$ ). Multiple pairwise comparisons of the 2013 data distinguished between two overlapping groups $(a, b)$ of relatively wetter sites (A1, A2, A3, B2, B3) and two overlapping groups (c, d) of relatively drier sets (B1, C1, C2, C3) (p<0.0001). Multiple pairwise comparisons of the smaller 2014 data set similarly distinguished a group (a) of relatively wetter sites (A1, A2, A3, B3) from a group (b) of relatively drier sites (B1, C1, C2. C3) although with a lower level of confidence $(\mathrm{p}<0.05)$. These latter groups are hereafter referred to as 'wet' and 'dry' sites and, based on the 2013 observations, site B2 was allocated to the 'dry' group.

\section{Variations in Root Density and Root Area Ratio with Depth and Moisture}

Root properties were investigated within $36510 \mathrm{~cm}$ depth intervals of 24 bank profiles distributed across 9 sites (Table 1). Although complete bank profiles were investigated at all sites apart from B2, and thus from the bank top to below the toe, reaching the ambient water table level in most cases, the number of $10 \mathrm{~cm}$ intervals varied greatly between profiles because of differences in the bank height. As a result, the depth of root profile investigated varied across the sites (Table 1) and, an important issue when interpreting some of the observations, those sites classified as wet had generally shallower bank profiles than those classified as dry (Figure 4).

Only 26 of the $10 \mathrm{~cm}$ intervals investigated contained no roots, of which 21 were located at dry sites and 5 at wet sites. Excluding the intervals with no roots, two root properties (root density in hundreds. $\mathrm{m}^{-2}$, hereafter termed 'density'; root area ratio in $\mathrm{cm}^{2} \cdot \mathrm{m}^{-2}$, hereafter termed 'RAR') showed skewed distributions with high variance at all monitored depths (Figure 4, upper graphs). When the information was split according to whether sites were wet (Figure 4, middle graphs) or dry (Figure 4, lower graphs), the wet sites showed a decline in density and possibly also a decline in RAR with depth whereas no such trend was apparent for the dry sites.

Relationships between the two root properties (including depth increments with no roots) and depth below the bank top were estimated using linear regression analyses. The regression analyses were only applied to data collected up to the $1.75 \mathrm{~m}$ mid-point depth interval, to ensure at least ten observations within each $10 \mathrm{~cm}$ depth interval and to confine the analysis largely to depths captured at both dry and wet sites. Analyses were applied to both untransformed, squared and $\log _{e}$-transformed values of density and RAR as the dependent variables and both simple regression relationships with depth as the independent variable, and multiple / quadratic regression relationships with depth and depth ${ }^{2}$ as the independent variables were estimated (Table 5). Because of the skewed frequency distributions of both density and RAR, regressions employing log-transformed dependent variables showed the most homoscedastic distribution of residuals and they also gave the highest coefficients of determination.

Multiple regression relationships between the root dependent variables and the depth independent variables were also estimated by incorporating a dummy variable 'WET', which took the value 1 for wet sites and 0 for dry sites. WET was introduced as an independent variable, and its interaction with depth and depth ${ }^{2}$ was assessed by also including WET*depth and WET*depth ${ }^{2}$ as independent variables, as appropriate. Table 6 lists only those regression relationships which were statistically significant $(\mathrm{p}<0.05$ for the intercept and all slope coefficients) and increased the coefficient of determination (adjusted for degrees of freedom) when compared with the simpler relationships listed in Table 5. Once more the relationships estimated with log-transformed dependent variables showed the highest coefficients of determination as well as displaying the most homoscedastic residuals. These statistically significant relationships ( $\mathrm{p}<0.001$ for both intercept and slope coefficients) explained $29.0 \%$ and $14.4 \%$ of the variance in $\log _{e}($ density +1$)$ and $\log _{e}(R A R+1)$, respectively.

\section{Variations in Root Density and Root Area Ratio with Sediment Properties}

Kruskal Wallis tests were used to explore whether there were statistically significant differences in root properties within sediments of different type. The results of these analyses are reported in Table 7 and show strong links between sediment class and contained roots. Both density and RAR of all roots is highest in the finest sediments (class 5 for density and classes 4 and 5 for RAR) and lowest in the coarsest sediments (classes 1 and 2) but the highest median root diameters are found in intermediate sediment classes 4 and 3, dominated by gravel with some sand and by a sand-gravel mixture, respectively. These differences in root properties with sediment class persist when roots are separated into fine and coarse subgroups, suggesting no major differences in the distribution of 
finer or coarser roots across different sediment classes. Furthermore, the link between root properties and both depth and moisture is further indicated by the increased presence of coarser sediments (classes 1, 2 and 3) with increasing depth (i.e. higher density and RAR associated with finer sediment classes 4 and 5, which tend to occur nearer the bank top) and lower moisture content (i.e. higher density and RAR associated with finer sediment classes 4 and 5, which also have a higher water content).

\section{Variations in Root Density and Root Area Ratio with Depth, Moisture and Sediment Properties}

The contribution of all three potential controls (depth, moisture, sediment properties) on root density and RAR was explored using stepwise multiple regression analysis. Twenty two potential predictors were incorporated including six dummy variables (WET, class1, class2, class3, class4, class5), five interactions between the dummy variables (WETclass1, WETclass2, WETclass3, WETclass4, WETclass5), six interactions between each of the dummy variables and depth (e.g. WETdepth, class1depth), five interactions between pairs of dummy variables and depth (e.g. WETclassdepth). The dummy variables reflected the classifications of moisture and sediment described in the previous sections. The dependent variables were $\log _{\mathrm{e}}$-transformed to deliver residuals that were homoscedastic and normally distributed. The regression model with the highest value of $\mathrm{R}^{2}$, adjusted for degrees of freedom, and incorporating only statistically significant $(\mathrm{p}<0.05)$ slope coefficients was selected.

The multiple regression model that best-describes root density is:

$\log _{\mathrm{e}}($ density +1$)=2.052+1.433$ WET -0.508 class $2+1.256$ class $5-0.222$ depth

$$
\begin{aligned}
& (p<0.001)(p<0.001) \quad(p<0.001) \quad(p<0.001) \quad(p=0.034) \\
& -0.924 \text { WETdepth }-1.230 \text { WETclass5depth } \\
& (p<0.001) \quad(p<0.001) \\
& R^{2}(\text { adj })=0.362
\end{aligned}
$$

From this model, the relationship between density and sediment calibre for drier and wetter sites is as follows:

Drier sites

$$
\begin{array}{ll}
\text { class } 1: & \log _{\mathrm{e}}(\text { density }+1)=2.052-0.222 \text { depth } \\
\text { class2: } & \log _{\mathrm{e}}(\text { density }+1)=1.544-0.222 \text { depth } \\
\text { class3: } & \log _{\mathrm{e}}(\text { density }+1)=2.052-0.222 \text { depth } \\
\text { class4: } & \log _{\mathrm{e}}(\text { density }+1)=2.052-0.222 \text { depth } \\
\text { class5: } & \log _{\mathrm{e}}(\text { density }+1)=3.308-0.222 \text { depth } \\
\text { class1: } & \log _{\mathrm{e}}(\text { density }+1)=3.485-1.146 \text { depth } \\
\text { class2: } & \log _{\mathrm{e}}(\text { density }+1)=2.977-1.146 \text { depth } \\
\text { class3: } & \log _{\mathrm{e}}(\text { density }+1)=3.485-1.146 \text { depth } \\
\text { class4: } & \log _{\mathrm{e}}(\text { density }+1)=3.485-1.146 \text { depth } \\
\text { class5: } & \log _{\mathrm{e}}(\text { density }+1)=4.741-2.376 \text { depth }
\end{array}
$$$$
\text { Wetter sites class } 1: \log _{\mathrm{e}}(\text { density }+1)=3.485-1.146 \text { depth }
$$

Thus it appears that root density declines with depth across all sites but that this explanatory variable on its own has the weakest statistical significance $(\mathrm{p}=0.034)$. Root density is also generally higher in the upper part of the sediment profile at wetter sites but declines more rapidly with depth than at drier sites. Root density is highest in the upper profile and declines most rapidly with depth within the finest sediments (class5) at wetter sites. Root density is generally lower within relatively coarse sediments (class2) and is lowest within these sediments at drier sites.

The multiple regression model that best-describes RAR is: 
$\log _{\mathrm{e}}(\mathrm{RAR}+1)=2.925+0.653$ WET -2.189 class $1-2.477$ class $2-1.398$ class 4

$$
\begin{aligned}
& (p<0.001)(p<0.001) \quad(p<0.001) \quad(p<0.001) \quad(p<0.001) \\
& \text { - 1.160 WETclass3 - } 1.223 \text { class3depth - 1.841 WET class5depth } \\
& (\mathrm{p}=0.047) \quad(\mathrm{p}<0.001) \quad(\mathrm{p}<0.001) \\
& \mathrm{R}^{2}(\operatorname{adj})=0.260
\end{aligned}
$$

From this model, the relationship between RAR and sediment type for drier and wetter sites is as follows:

Drier sites

$$
\begin{array}{ll}
\text { class } 1: & \log _{\mathrm{e}}(\mathrm{RAR}+1)=0.736 \\
\text { class2: } & \log _{\mathrm{e}}(\mathrm{RAR}+1)=0.448 \\
\text { class3: } & \log _{\mathrm{e}}(\mathrm{RAR}+1)=2.925-1.223 \text { depth } \\
\text { class4: } & \log _{\mathrm{e}}(\mathrm{RAR}+1)=1.527 \\
\text { class5: } & \log _{\mathrm{e}}(\mathrm{RAR}+1)=2.925 \\
\text { class 1: } & \log _{\mathrm{e}}(\mathrm{RAR}+1)=1.389 \\
\text { class2: } & \log _{\mathrm{e}}(\mathrm{RAR}+1)=1.101 \\
\text { class3: } & \log _{\mathrm{e}}(\mathrm{RAR}+1)=2.418-1.223 \text { depth } \\
\text { class4: } & \log _{\mathrm{e}}(\mathrm{RAR}+1)=2.180 \\
\text { class5: } & \log _{\mathrm{e}}(\mathrm{RAR}+1)=3.578-1.841 \text { depth }
\end{array}
$$

Wetter sites

Thus it appears that RAR does not decline generally with depth but is higher at wetter than at drier sites. RAR is also lower where coarser sediments are present (class1, class2) and shows a decrease with depth at sites with intermediate calibre sediments (class3) and also with the finest sediments at wetter sites (class5).

\section{DISCUSSION}

This study has focussed on the roots of Populus nigra L., the locally dominant riparian tree species along the Tagliamento river, although all roots within the bank sediment profile were assessed. Perhaps most importantly (and further supported by excavations of complete coarse root systems reported by Holloway et al., 2016 a, b), roots continued in significant numbers and cross-sectional area beyond the maximum sampling depth in most of the profiles investigated, suggesting that the investigated systems are unusually deeply-rooted. The observed profiles compare favourably with desert and temperate coniferous forest biomes, which show the deepest profiles in the global analysis of Jackson et al. (1996). None of the riparian species studied by Simon and Collison (2002) were found to root below $0.9 \mathrm{~m}$, although their sites were loess sediments, which were presumably finer-grained and slower-draining than those along the Tagliamento. The observed deep root distributions may be due to water limitation in these counter-intuitively xeric, free-draining riparian soils - necessitating access to the alluvial aquifer throughout the growing season or possibly simply reflecting the rapid accretion of sediment around the developing vegetation cover and thus the progressive burial of the roots.

Observations of root profiles within the river banks of the Tagliamento have also revealed enormous variability both within and between the 24 profiles that were excavated. It is important to recognise that such variability exists if we are to place error margins on any generalised relationships that may be proposed based upon explanatory variables such as depth and their implications for the erodibility and stability of river banks. Nevertheless, it has been possible to demonstrate evidence for the influence of the environmental characteristics that were addressed by the three research questions posed in the introduction to this paper.

\section{Question 1: Is there an association between riparian tree root properties and depth within the bank profile?}


Statistically-significant regression relationships between riparian tree root properties and depth were estimated, although the coefficients of determination were rather small. Specifically, $15 \%$ of the variance in $\log _{e}($ density +1$)$ and $8 \%$ of the variance in $\log _{\mathrm{e}}(\mathrm{RAR}+1)$ were explained by a linear relationship with depth. This confirms a logarithmic decline in density and RAR with depth across the sites investigated confirming the broad form of several continuous-depth models estimated for terrestrial species or broad vegetation types (e.g. Gerwitz and Page, 1974, Jackson et al., 1996, Schenk and Jackson, 2002), although note that these models generally consider cumulative root biomass. It also suggests that, in addition to inherent (phenotypic) variability in root systems (Danjon et al., 2013, Jung and McCouch, 2013), other factors are highly likely to be influencing root properties.

The $\log _{\mathrm{e}}$-transformation of the dependent variables in the regression analyses reflects the fact that both density and RAR were more variable in the upper parts of the investigated sediment profiles (analysed to $1.75 \mathrm{~m}$ depth, Figure 4). This higher variability in density is consistent with these upper horizons being a zone of reactive foraging by roots (Kembel et al., 2008, Adams et al., 2013). Variability in RAR is likely to be linked to root density and foraging, but may also be due to the existence of large structural roots and clonal expansion via adventitious, large suckering roots in black poplar in these upper layers.

\section{Question 2: Does the association between root properties and depth within the bank profile vary with moisture availability?}

When the investigated root profiles were split into two groups of wetter and drier sites, and a dummy variable (WET) was introduced into the regression analyses, the variance explained by the estimated regression models increased. Multiple linear regression relationships estimated between $\log _{\mathrm{e}}(\mathrm{density}+1)$ and $\log _{\mathrm{e}}(\mathrm{RAR}+1)$ as the dependent variables and depth, the dummy variable 'WET' and the interaction between 'WET' and depth as the independent variables explained $29 \%$ and $14 \%$ of the variance, respectively.

Thus, the assumed near-surface foraging strategy discussed above in relation to the higher and more variable values of density and RAR in the upper parts of the investigated root profiles is much more pronounced in wetter sites, but is still apparent in drier sites (Figure 4). Root density at drier sites shows a far greater range of densities below $1.0 \mathrm{~m}$ depth than wetter sites, suggesting perhaps a deeper zone of structural plasticity. The RAR distributions do not strongly match those of root density at drier sites and there is a much greater number of unusually large values of RAR due to isolated large-diameter roots throughout the depth range sampled. It is hypothesized that these may represent a perennial coarse structure from which short-lived, absorptive roots emanate where and when sediment conditions are favourable - a moisture-induced modulation of fundamental root system architecture similar to the mechanically-induced changes identified by Danjon et al. (2013). Higher values of RAR with depth may also reflect species other than $P$. nigra influencing the root profiles at these drier sites, and possibly older (larger) roots at depth reflecting the duration of gradual burial. However, Simon et al. (2006) found root area profiles much like the drier sites presented here around Salix lemmonnii Bebb, but much more similar to the wetter sites around Pinus contorta Douglas.

\section{Question 3: Is there an association between root properties and properties of the surrounding sediment?}

A combination of ordination (PCA), classification (HCA) and Kruskal Wallis tests identified five broad classes of sediment within the investigated bank profiles that were statistically significantly different from one another with respect to at least one of the eight sediment properties analysed (mean particle size $(\Phi), \mathrm{D}_{50}(\Phi), \mathrm{D}_{90}(\Phi)$, sorting $(\Phi)$, proportion gravel, proportion sand, proportion silt and clay, proportion organic).

Root density, RAR and median root diameter for all roots and also for the finer and coarser root fractions of the roots analysed were all found to vary to some extent with the type of sediment in which they were found. This is valuable information from the point of view of understanding root reinforcement, given that RAR forms the basis of bank stability models, and particularly given the fact that fine roots are disproportionately strong (Gray and Barker, 2004, Tosi, 2007, De Baets et al., 2008). From the observed associations between root properties and sediment class, it can be broadly concluded that the finest sediments (class 5) have the highest density of roots as well as the highest density of finer and coarser roots, and so are particularly well reinforced by roots in the studied river system. In the absence of roots, such finer material (which has a very low clay content) would be more readily eroded by water or wind, suggesting that these distributions represent an equalising effect on the stability of contrasting riparian sediments. Root density, RAR and median root diameter all generally decline as sediment coarsens, with the coarsest sediment (classes 1 and 2) showing the lowest values. However, the highest median root diameters in class 3 and 4 sediments may indicate a trade-off between slightly higher moisture stress relative to class 1 but a more favourable environment in terms of oxygen and nutrient availability (due to aerobic microbial activity), making root exploitation of these sediments worthwhile, but requiring thicker, more lignified and 
protected roots on average (Hishi, 2007). This association may also indicate lower investment in the finest roots, alternatively implying little actual exploitation of soil resources but perhaps more roots involved in transit of resources from more favourable areas, or differences in mycorrhizal status (Chen et al., 2016).

\section{Influence of interactions among the investigated environmental factors on root properties}

Root density and RAR have been shown to change with depth, moisture and sediment properties and so regression analysis was used to explore their relative contributions within the studied root-bank profiles. Stepwise multiple regression analysis identified the subset of variables that explained the greatest proportion of the variance in logtransformed root density and RAR whilst only incorporating those independent variables representing depth, moisture and sediment and their interactions that showed statistically significant slope coefficients. The regression models incorporating these variables explained over a third (36\%) of the variance in root density and over a quarter $(26 \%)$ of the variance in RAR.

Root density was found to show a consistent decline with depth, although this variable alone had the lowest statistical significance of those included in the regression model. Interactions between depth and moisture indicated that density tended to be higher near the surface and to decline more rapidly with depth at wetter sites, illustrating differing distribution (as opposed to total biomass allocation) dependent on moisture availability, as found by Imada et al. (2008) in comparable experimental systems. Furthermore, the finest sediments (class 5) showed the highest root densities near the surface and the sharpest decline with depth in comparison with the other sediment types, while coarser sediments (class 2) showed relatively lower root densities than other sediment types regardless of depth. These results suggest that site moisture and depth are the variables that give the most consistent indication of likely root density but that there are strong additional variations associated with the presence of fine or coarse sediments.

In contrast, of the three variables investigated, depth showed the least association with RAR, with no general variation in RAR with depth across the data set, highlighting the drawbacks of a simple depth decline model of root reinforcement. Instead, wetter sites showed consistently higher values of RAR than drier sites, indicating that moisture is the most important explanatory variable across the studied profiles. Nevertheless, a decline in RAR with depth was identified in association with two types of sediment, classes 3 and 5, but the latter was only found at wetter sites.

\section{CONCLUSIONS}

This study has revealed a range of properties of riparian root profiles within the Populus nigra dominated margins of the Tagliamento river, Italy.

Although root density was found to decline with depth below the riparian ground surface, as suggested by studies in other environments with different vegetation cover, RAR showed limited evidence of such a decline. Furthermore, roots penetrated to considerable depth such that most of the excavated bank profiles did not reach the base of the root systems that were present.

Deep rooting reflects the requirement of tree roots to penetrate to the water table in the relatively xeric environment of free-draining riparian sediments, and also the fact that as the vegetation develops it traps alluvial and wind-blown sediments so that the ground surface aggrades leaving root sediments at greater depths as well as within the newly aggraded sediments. The fact that roots are denser near the surface and decline more rapidly with depth in moister sites, reflects the lower dependence of trees on access to the water table in moister environments.

The complex history of sediment aggradation by different processes (flowing water, standing water, wind) interspersed with sediment erosion, results in complex sedimentary sequences within river banks, particularly along a high energy river system such as the Tagliamento. Since finer sediments are not only more moistureretentive but were found to contain organic material, they are a better source of moisture and nutrients for tree roots, explaining the higher densities of roots in these sediments and the complex profiles of roots found in river banks comprised of layers of sediment of highly varying calibre.

The clear response of root density to depth, moisture and sediment type was not as evident in the patterns observed for RAR. This suggests that root size shows patterns that to some extent complement those of root number or density. This can be explained by adjustments in the architecture of roots, where coarser, less cohesive sediments show relatively more coarse structural roots that provide anchorage, whereas finer sediments show more fine roots that forage for resources. 
With regards to the general issue of the prediction of root reinforcement in river banks, in addition to models that emphasise a decline in density and RAR with depth, the associations between root variables and sediment calibre are encouraging. Indeed, the significant influence of sediment characteristics on root properties is an important finding of this study, since it disrupts any simple depth-related trends in complex riparian sediments. Furthermore, this study highlights the enormous variability that remains unexplained by depth, moisture and sediment calibre, even when studied in relation to a single riparian tree species on a single river system, and so caution must be exercised in such modelling. Approximately two-thirds of the variance remained unexplained for root density and three-quarters for RAR in the present study. However, the relationships revealed offer the potential for more detailed modelling of the enhancement of bank stability by roots. For example, the Bank Stability and Toe Erosion Model (BSTEM) developed by Pollen-Bankhead and Simon (2009) and others already includes explicit treatment of sedimentary strata and simple root depth distributions, and so it may be relatively straightforward, given more detailed data on root-sediment associations, to modify the root depth distributions based on stratigraphic data.

\section{ACKNOWLEDGEMENTS}

James Holloway's research is funded by the SMART Joint Doctoral Programme (Science for MAnagement of Rivers and their Tidal systems), which is financed by the Erasmus Mundus Programme of the European Union.

\section{REFERENCES}

Abernethy B, Rutherfurd ID. 2000. The effect of riparian tree roots on the mass-stability of riverbanks. Earth Surface Processes and Landforms, 25(9): 921-937.

Abernethy B, Rutherfurd ID. 2001. The distribution and strength of riparian tree roots in relation to riverbank reinforcement. Hydrological Processes, 15(1): 63-79.

Adams TS, McCormack ML, Eissenstat DM. 2013. Foraging strategies in trees of different root morphology: The role of root lifespan. Tree Physiology 33(9): 940-948.

Bischetti GB, Chiaradia EA, Simonato T, Speziali B, Vitali B, Vullo P, Zocco A. 2005. Root strength and root area ratio of forest species in Lombardy (Northern Italy). Plant and Soil 278: 11-22.

Burylo M, Rey F, Mathys N, Dutoit T. 2012. Plant root traits affecting the resistance of soils to concentrated flow erosion. Earth Surface Processes and Landforms, 37(14): 1463-1470.

Chen W, Koide RT, Adams TS, DeForest JL, Cheng L, Eissenstat DM. 2016. Root morphology and mycorrhizal symbioses together shape nutrient foraging strategies of temperate trees. PNAS 113 (31): 8741-8746.

Danjon F, Khuder H, Stokes A. 2013. Deep phenotyping of coarse root architecture in R. Pseudoacacia reveals that tree root system plasticity is confined within its architectural model. PLoS ONE 8(12): e83548. DOI:10.1371/journal.pone.0083548.

De Baets S, Torri D, Poesen J, Salvador MP, Meersmans J. 2008. Modelling increased soil cohesion due to roots with EUROSEM. Earth Surface Processes and Landforms, 33(13): 1948-1963.

Docker BB, Hubble TCT. 2008. Quantifying root-reinforcement of river bank soils by four Australian tree species. Geomorphology, 100(3-4): 401-418.

Edmaier K, Burlando P, Perona P. 2011. Mechanisms of vegetation uprooting by flow in alluvial non-cohesive sediment. Hydrology and Earth System Sciences 15: 1615-1627.

Gerwitz A, Page ER. 1974. An empirical mathematical model to describe plant root systems. Journal of Applied Ecology, 11: 773-781.

Giadrossich F, Schwarz M, Cohen D, Preti F, Or D. 2013. Mechanical interactions between neighbouring roots during pullout tests. Plant and Soil, 367: 391-406.

Gray DH, Barker D. 2004. Root-soil mechanics and interactions. In Riparian Vegetation and Fluvial Geomorphology, Water Science and Application, Bennett SJ, Simon A. (eds). American Geophysical Union: Washington D.C.; 113-123.

Gyssels G, Poesen J, Bochet E, Li Y. 2005. Impact of plant roots on the resistance of soils to erosion by water: a review. Progress in Physical Geography, 29: 189-217.

Hathaway RL, Penny D. 1975. Root Strength in Some Populus and Salix Clones. . New Zealand Journal of Botany 13: 333-344. 
Hishi T. 2007. Heterogeneity of individual roots within the fine root architecture: Causal links between physiological and ecosystem functions. Journal of Forest Research 12(2): 126-133.

Holloway JV, Rillig MC, Gurnell AM. 2016a. Underground riparian wood: Buried stem and coarse root structures of Black Poplar (Populus nigra L.). Geomorphology, early view, http://dx.doi.org/10.1016/j.geomorph.2016.08.002

Holloway JV, Rillig MC, Gurnell AM. 2016b. Underground riparian wood: Reconstructing the processes influencing buried stem and coarse root structures of Black Poplar (Populus nigra L.). Geomorphology, early view, http://dx.doi.org/10.1016/j.geomorph.2016.07.027

Hubble TCT, Docker BB, Rutherfurd ID. 2010. The role of riparian trees in maintaining riverbank stability: A review of Australian experience and practice Ecological Engineering, 36: 292-304.

Imada S, Yamanaka N, Tamai S. 2008. Water table depth affects Populus alba fine root growth and whole plant biomass. Functional Ecology 22(6): 1018-1026.

Jackson RB, Canadell J, Ehleringer JR, Mooney HA, Sala OE, Schulze ED. 1996. A global analysis of root distributions for terrestrial biomes. Oecologia, 108: 389-411.

Jung JKH, McCouch S. 2013. Getting to the roots of it: Genetic and hormonal control of root architecture. Frontiers in Plant Science, 4: DOI: 10.3389/fpls.2013.00186.

Kean JW, Smith J.D. 2004. Flow and boundary shear stress in channels with woody bank vegetation. In Riparian Vegetation and Fluvial Geomorphology. Water Science and Application, Bennett SJ, Simon A. (eds). American Geophysical Union: Washington, D.C.; 237-252.

Kembel SW, De Kroon H, Cahill Jr JF, Mommer L. 2008. Improving the scale and precision of hypotheses to explain root foraging ability. Annals of Botany 101(9): 1295-1301.

Maeght JL, Rewald B, Pierret A. 2013. How to study deep roots-and why it matters. Frontiers in Plant Science, 4: DOI: $10.3389 /$ fpls.2013.00299.

Mallik AU, Rasid H. 1993. Root-shoot characteristics of riparian plants in a flood control channel: implications for bank stabilization. Ecogical Engineering, 2: 149-158.

Monteith JL, Huda AKS, Midya D. 1989. RESCAP: A resource capture model for sorghum and pearl millet In Modeling the Growth and Development of Sorghum and Pearl Millet, Virimane SM, Tandon HLS, Alagarswamy G. (eds). ICRISAT: Patancheru, India; 30-34.

Naumburg E, Mata-Gonzalez R, Hunter RG, McLendon T, Martin DW. 2005. Phreatophytic Vegetation and Groundwater Fluctuations: A Review of Current Research and Application of Ecosystem Response Modeling with an Emphasis on Great Basin Vegetation. Environmental Management, 35(6): 726-740.

Pollen N. 2007. Temporal and spatial variability in root reinforcement of streambanks: Accounting for soil shear strength and moisture Catena, 69: 197-205.

Pollen N, Simon A, Collison A. 2004. Advances in assessing the mechanical and hydrologic effects of riparian vegetation on streambank stability. In Riparian Vegetation and Fluvial Geomorphology, Water Science and Application, Bennett SJ, Simon A. (eds). American Geophysical Union: Washington, D.C.; 125-139.

Pollen-Bankhead N, Simon A. 2010. Hydrologic and hydraulic effects of riparian root networks on streambank stability: Is mechanical root-reinforcement the whole story? Geomorphology, 116(3-4): 353-362.

Rood S, Bigelow S, Hall A. 2011. Root architecture of riparian trees: river cut-banks provide natural hydraulic excavation, revealing that cottonwoods are facultative phreatophytes. Trees, 25(5): 907-917.

Schenk HJ, Jackson RB. 2002. The global biogeography of roots. Ecological Monographs, 72: 311-328.

Simon A, Collison AJC. 2002. Quantifying the mechanical and hydrologic effects of riparian vegetation on streambank stability. Earth Surface Processes and Landforms, 27(5): 527-546.

Simon A, Pollen N, Langendoen EJ. 2006. Influence of two woody riparian species on critical conditions for streambank stability: Upper Truckee River, California. Journal of the American Water Resources Association, 42(1): 99-113.

Singer MB, Sargeant CI, Piégay H, Riquier J, Wilson RJS, Evans CM. 2014. Floodplain ecohydrology: Climatic, anthropogenic, and local physical controls on partitioning of water sources to riparian trees. Water Resources Research, 50: 4490-4513. 
Smith DG. 1976. Effect of vegetation on lateral migration of anastomosed channels of a glacial meltwater river. Geological Society of America Bulletin, 87: 857-860.

Snyder KA, Williams DG. 2007. Root allocation and water uptake patterns in riparian tree saplings: Responses to irrigation and defoliation. Forest Ecology and Management, 246(2-3): 222-231.

Stokes A, Mattheck C. 1996. Variation of wood strength in tree roots. Journal of Experimental Botany, 47: 693699.

Stromberg JC. 2013. Root patterns and hydrogeomorphic niches of riparian plants in the American Southwest. Journal of Arid Environments 94: 1-9.

Tabacchi E, Lambs L, Guilloy H, Planty-Tabacchi A.-M, Muller E, Décamps H. 2000. Impacts of riparian vegetation on hydrological processes. Hydrological Processes, 14(16-17): 2959-2976.

Thomas RE, Pollen-Bankhead N. 2010. Modeling root-reinforcement with a fiber-bundle model and Monte Carlo simulation. Ecological Engineering, 36: 47-61.

Tosi M. 2007. Root tensile strength relationships and their slope stability implications of three shrub species in the Northern Apennines (Italy). Geomorphology Geomorphology, 87: 268-283.

Vennetier M, Zanetti C, Meriaux P, Mary B. 2015. Tree root architecture: new insights from a comprehensive study on dikes Plant and Soil, 387: 81-101.

Watson AJ, Marden M. 2004. Live root-wood tensile strengths of some common New Zealand indigenous and plantation tree species. New Zealand Journal of Forestry Science 34: 344-353.

Zanetti C, Vennetier M, Mériaux P, Provansal M. 2015. Plasticity of tree root system structure in contrasting soil materials and environmental conditions. Plant and Soil, 387: 21-35. 
Table 1: Number of bank profiles, depth range and depth intervals sampled at the nine sampling sites and site moisture class

\begin{tabular}{cccccccc}
\hline Site & $\begin{array}{c}\text { Wet or } \\
\text { Dry } \\
\text { Site }\end{array}$ & $\begin{array}{c}\text { Number } \\
\text { of bank } \\
\text { profiles } \\
\text { sampled }\end{array}$ & $\begin{array}{c}\text { Number } \\
\text { of } \mathbf{1 0} \mathbf{~ c m} \\
\text { depth } \\
\text { intervals } \\
\text { sampled }\end{array}$ & $\begin{array}{c}\text { Depth } \\
\text { range } \\
\text { sampled at } \\
\text { profile 1 } \\
\text { (m from } \\
\text { bank top) }\end{array}$ & $\begin{array}{c}\text { Depth } \\
\text { range } \\
\text { sampled at } \\
\text { profile 2 } \\
\text { (m from } \\
\text { bank top) }\end{array}$ & $\begin{array}{c}\text { Depth } \\
\text { range } \\
\text { sampled at } \\
\text { profile 3 } \\
\text { (m from } \\
\text { bank top) }\end{array}$ & $\begin{array}{c}\text { Depth } \\
\text { range } \\
\text { sampled at } \\
\text { profile 4 } \\
\text { (m from } \\
\text { bank top) }\end{array}$ \\
\hline A1 & W & 4 & 54 & $0.0-1.5$ & $0.0-1.5$ & $0.0-0.8$ & $0.0-1.5$ \\
A2 & W & 2 & 29 & $0.0-1.5$ & $0.0-1.4$ & & \\
A3 & W & 2 & 36 & $0.0-1.7$ & $0.0-1.6$ & & \\
B1 & D & 4 & 39 & $0.0-1.0$ & $0.0-1.0$ & $0.0-1.0$ & $0.0-1.0$ \\
B2 & D & 2 & 27 & $1.0-2.0 *$ & $1.1-2.4 *$ & & \\
B3 & W & 2 & 33 & $0.0-1.7$ & $0.0-1.6$ & & \\
C1 & D & 4 & 67 & $0.0-2.0$ & $0.0-2.0$ & $0.0-2.0$ & $0.0-0.7$ \\
C2 & D & 2 & 44 & $0.0-2.1$ & $0.0-2.3$ & & \\
C3 & D & 2 & 36 & $0.0-1.7$ & $0.0-1.9$ & & \\
\hline
\end{tabular}

* Site damaged by flooding before measurements were obtained for the upper parts of these profiles

Table 2: Summary statistics for organic matter content and seven particle size properties of 185 sediment samples.

\begin{tabular}{ccccccccc}
\hline Statistic & $\begin{array}{c}\text { Mean } \\
\text { Particle } \\
\text { Size }(\Phi)^{*}\end{array}$ & $\begin{array}{c}\mathrm{D}_{50} \\
(\Phi)\end{array}$ & $\begin{array}{c}\mathrm{D}_{90} \\
(\Phi)\end{array}$ & $\begin{array}{c}\text { Sorting } \\
(\Phi)^{*}\end{array}$ & $\begin{array}{c}\% \\
\text { Gravel }\end{array}$ & $\begin{array}{c}\% \\
\text { Sand }\end{array}$ & $\begin{array}{c}\% \\
\text { Silt+Clay }\end{array}$ & $\begin{array}{c}\% \\
\text { Organic } \\
\text { matter }\end{array}$ \\
\hline Median & 3.57 & 3.13 & 6.66 & 1.84 & 0.00 & 37.8 & 30.3 & 1.50 \\
Mean & 2.62 & 2.08 & 5.61 & 1.61 & 26.2 & 40.9 & 32.9 & 1.57 \\
$\begin{array}{c}\text { Standard } \\
\text { deviation }\end{array}$ & 2.32 & 2.51 & 2.99 & 0.73 & 37.5 & 24.9 & 25.1 & 1.28 \\
Maximum & 6.30 & 5.80 & 10.1 & 3.25 & 96.7 & 90.3 & 86.4 & 7.93 \\
Minimum & -1.18 & -1.94 & -3.11 & -0.64 & 0.0 & 1.08 & 1.28 & 0.05 \\
\hline
\end{tabular}

* calculated using the Folk and Ward (1956) method

Note that the $-\log _{2}$ transformation that expresses particle size in phi units leads to a value of 0 for particles of $2 \mathrm{~mm}$ diameter with positive values for particles smaller than $2 \mathrm{~mm}$ diameter and negative values for particles larger than $2 \mathrm{~mm}$ diameter 
Table 3: Eigenvalues, percentage variability explained and loadings of variables on the first three components of a Principal Components Analysis of eight main sediment variables, as distributed among 350 root sampling intervals.

\begin{tabular}{lccc}
\hline & PC 1 & PC 2 & PC 3 \\
\hline Eigenvalue & 6.37 & 0.97 & 0.43 \\
Variability (\%) & 79.62 & 12.16 & 5.37 \\
Cumulative variability (\%) & 79.62 & 91.78 & 97.15 \\
\hline Variable loadings & & & \\
Mean $(\Phi)$ & $\mathbf{0 . 9 8 0}$ & -0.124 & -0.076 \\
D50 $(\Phi)$ & $\mathbf{0 . 9 4 8}$ & -0.137 & -0.200 \\
D90 $(\Phi)$ & $\mathbf{0 . 9 7 2}$ & -0.169 & 0.054 \\
Sorting $(\Phi)$ & $\mathbf{0 . 8 0 1}$ & -0.124 & 0.584 \\
\% Gravel & $\mathbf{0 . 9 0 3}$ & -0.366 & 0.112 \\
\% Sand & 0.518 & $\mathbf{0 . 8 4 6}$ & 0.074 \\
\% Silt+clay & $\mathbf{0 . 9 6 7}$ & -0.201 & $-0.0751 .50) /$ \\
\% Organic & $\mathbf{0 . 9 5 3}$ & -0.062 & -0.127 \\
\hline
\end{tabular}

Loadings greater than 0.8 are in bold font 
Table 4: Centroids of five classes of eight sediment properties identified by applying Hierarchical Cluster Analysis to sediment data for $35010 \mathrm{~cm}$ depth sampling intervals.

\begin{tabular}{ccccccccc}
\hline Cluster & Mean $(\Phi)$ & $D_{50}(\Phi)$ & $D_{90}(\Phi)$ & Sorting $(\Phi)$ & $\begin{array}{c}\text { Proportion } \\
\text { Gravel }\end{array}$ & $\begin{array}{c}\text { Proportion } \\
\text { Sand }\end{array}$ & $\begin{array}{c}\text { Proportion } \\
\text { Silt+clay }\end{array}$ & $\begin{array}{c}\text { Proportion } \\
\text { Organic }\end{array}$ \\
\hline 1 & -1.12 & -1.16 & -1.22 & -0.07 & 0.91 & 0.06 & 0.03 & 0.00 \\
2 & -0.33 & -1.24 & 2.43 & 0.90 & 0.77 & 0.17 & 0.06 & 0.00 \\
3 & 1.09 & 0.29 & 4.72 & 1.95 & 0.46 & 0.39 & 0.16 & 0.01 \\
4 & 3.76 & 3.37 & 6.84 & 1.85 & 0.01 & 0.62 & 0.37 & 0.02 \\
5 & 5.11 & 4.70 & 8.76 & 2.13 & 0.00 & 0.31 & 0.69 & 0.04 \\
\hline
\end{tabular}


Table 5: Linear regression models incorporating root density (hundreds. $\mathrm{m}^{-2}$ ) or root area ratio (RAR in $\mathrm{cm}^{2} \cdot \mathrm{m}^{-2}$ ) as the dependent variable and (i) depth (m) and (ii) depth and depth ${ }^{2}$ as the independent variable (s). (Note: Models are estimated to $1.8 \mathrm{~m}$ depth and only those that are statistically significant $(p<0.05)$ are listed)

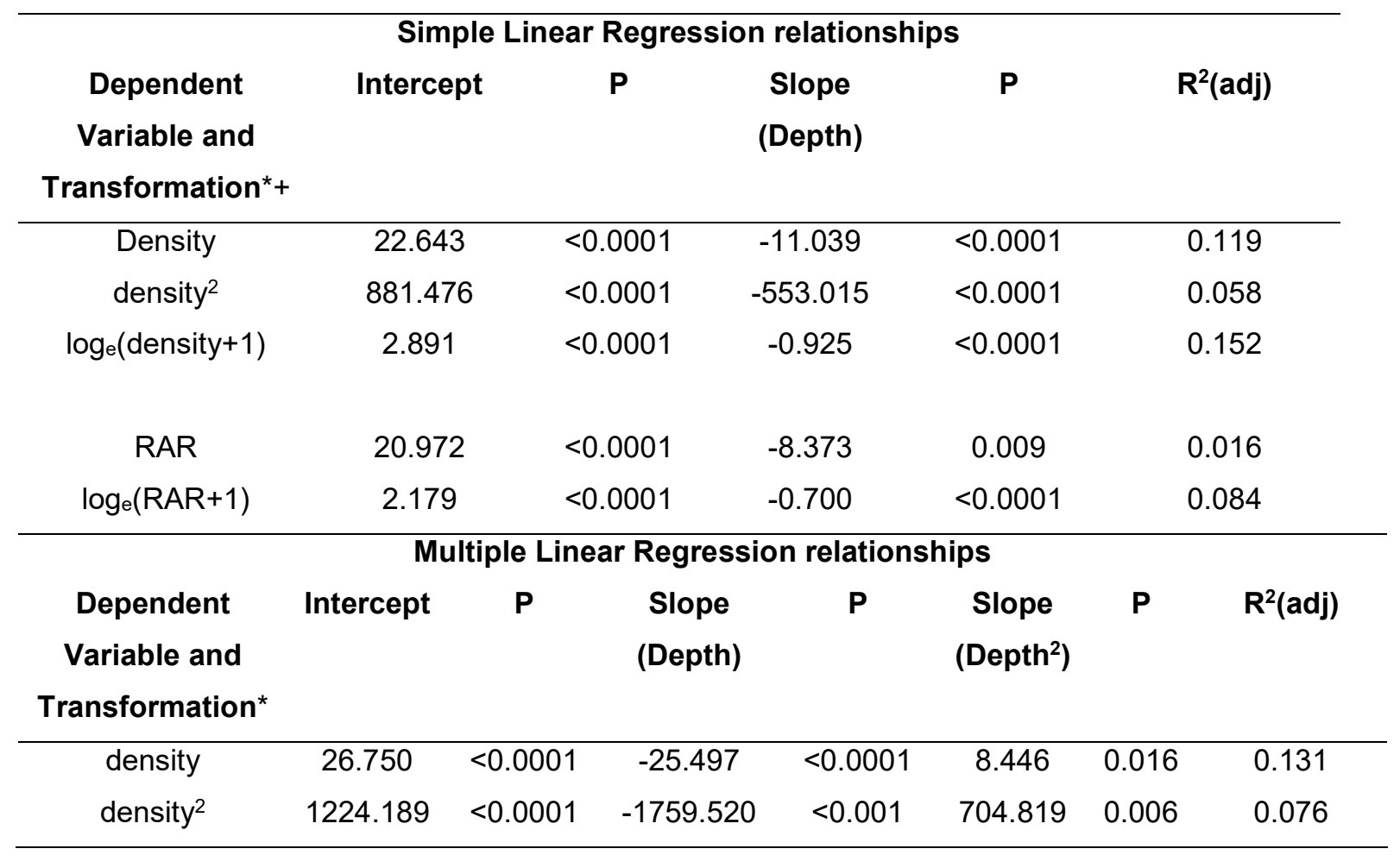

+1 was added to density and RAR prior to In transformation to remove zeros

* The simple regression of $(R A R)^{2}$ on depth was not statistically significant and no multiple regression relationships including RAR as the dependent variable were statistically significant 
Table 6: Multiple linear regression models incorporating Root Density (hundreds $\mathrm{m}^{-2}$ ) or Root Area Ratio $\left(\mathrm{cm}^{2} \mathrm{~m}^{-2}\right.$ ) as the dependent variable and Depth $(\mathrm{m})$, Wet and Wet*Depth as the independent variables, where Wet is a dummy variable which takes the value 1 for wetter sites and 0 for drier sites.

(Note: Models are estimated to $1.8 \mathrm{~m}$ depth and only those that are statistically significant $(p<0.05)$ and show an increase in $R^{2}$ (adjusted for degrees of freedom) in comparison with the simpler models shown in Table 6 are listed).

\begin{tabular}{|c|c|c|c|c|c|c|c|c|c|}
\hline $\begin{array}{l}\text { Trans- } \\
\text { Formation }\end{array}$ & Intercept & $\mathbf{P}$ & $\begin{array}{l}\text { Slope } \\
\text { (WET) }\end{array}$ & $\mathbf{P}$ & $\begin{array}{c}\text { Slope } \\
\text { (Depth) }\end{array}$ & $\mathbf{P}$ & $\begin{array}{c}\text { Slope } \\
\text { (WET*Depth) }\end{array}$ & $\mathbf{P}$ & $R^{2}$ (adj) \\
\hline \multicolumn{10}{|l|}{ Root Density } \\
\hline Density & 9.185 & $<0.0001$ & 27.294 & $<0.0001$ & - & - & -22.012 & $<0.0001$ & 0.289 \\
\hline density $^{2}$ & 194.878 & 0.008 & 1558.329 & $<0.0001$ & - & - & -1310.922 & $<0.0001$ & 0.187 \\
\hline $\log _{\mathrm{e}}($ density+1) & 2.281 & $<0.0001$ & 1.343 & $<0.0001$ & -0.577 & $<0.0001$ & -0.784 & $<0.001$ & 0.290 \\
\hline \multicolumn{10}{|l|}{ Root Area Ratio } \\
\hline $\log _{e}(R A R+1)$ & 1.946 & $<0.0001$ & 0.650 & $<0.0001$ & -0.800 & $<0.0001$ & - & - & 0.144 \\
\hline
\end{tabular}


Table 7: Statistically significant differences $(p<0.01)$ in root properties and two abiotic variables across the five sediment classes.

3

\begin{tabular}{llcc}
\hline Variable type & \multicolumn{1}{c}{ Variable name } & $\begin{array}{c}\text { Kruskall-Wallis } \boldsymbol{K} \\
\mathbf{( 4} \text { d.f.) } \\
\text { (all significant } \\
\mathbf{p}<\mathbf{0 . 0 1 )}\end{array}$ & $\begin{array}{c}\text { Statistically significantly } \\
\text { differences among sediment } \\
\text { classes } \\
(\mathbf{p}<\mathbf{0 . 0 1})^{*}\end{array}$ \\
\hline Root Variables & Root density & 78 & $5>431>2$ \\
& RAR & 80 & $543>21$ \\
& Median root diameter & 29 & $43>21$ \\
& Fine root density & 59 & $5>4>321$ \\
& Fine root RAR & 53 & $5>4>321$ \\
& Median fine root diameter & 19 & $3>214>2$ \\
& Coarse root density & & $5>321$ \\
& Coarse RAR & 40 & $54>2$ \\
& Median coarse root diameter & 25 & $43>2$ \\
Abiotic Variables & Depth & 17 & $321>54$ \\
& 2013 Sediment moisture content & 155 & $54>321$ \\
\hline
\end{tabular}

$4{ }^{*}$ following multiple pairwise comparisons using Dunn's procedure with Bonferroni correction 


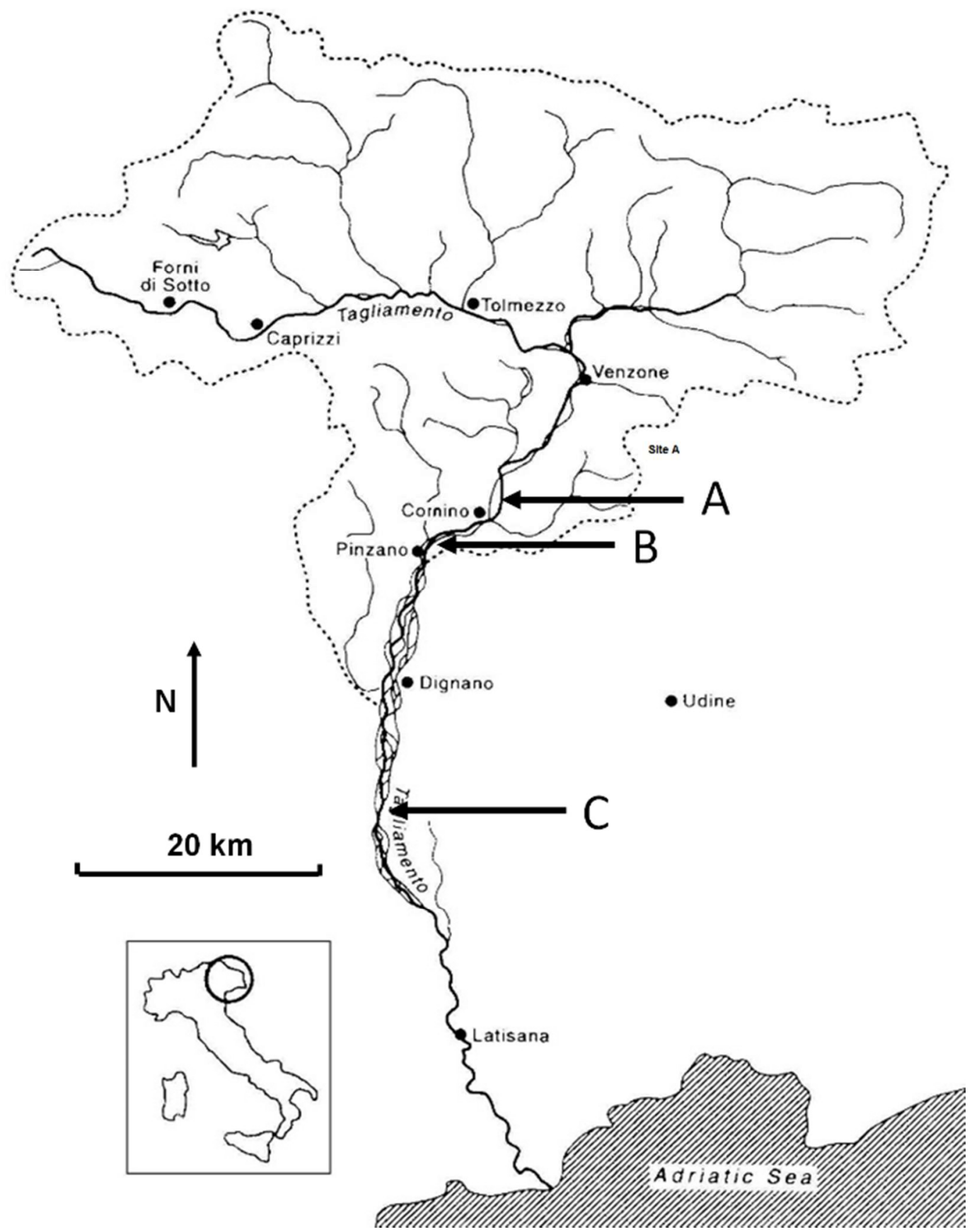

Figure 1. The catchment of the Tagliamento River, NE Italy, located the three study locations (A, B, $8 \quad$ C) where root profiles were investigated. 


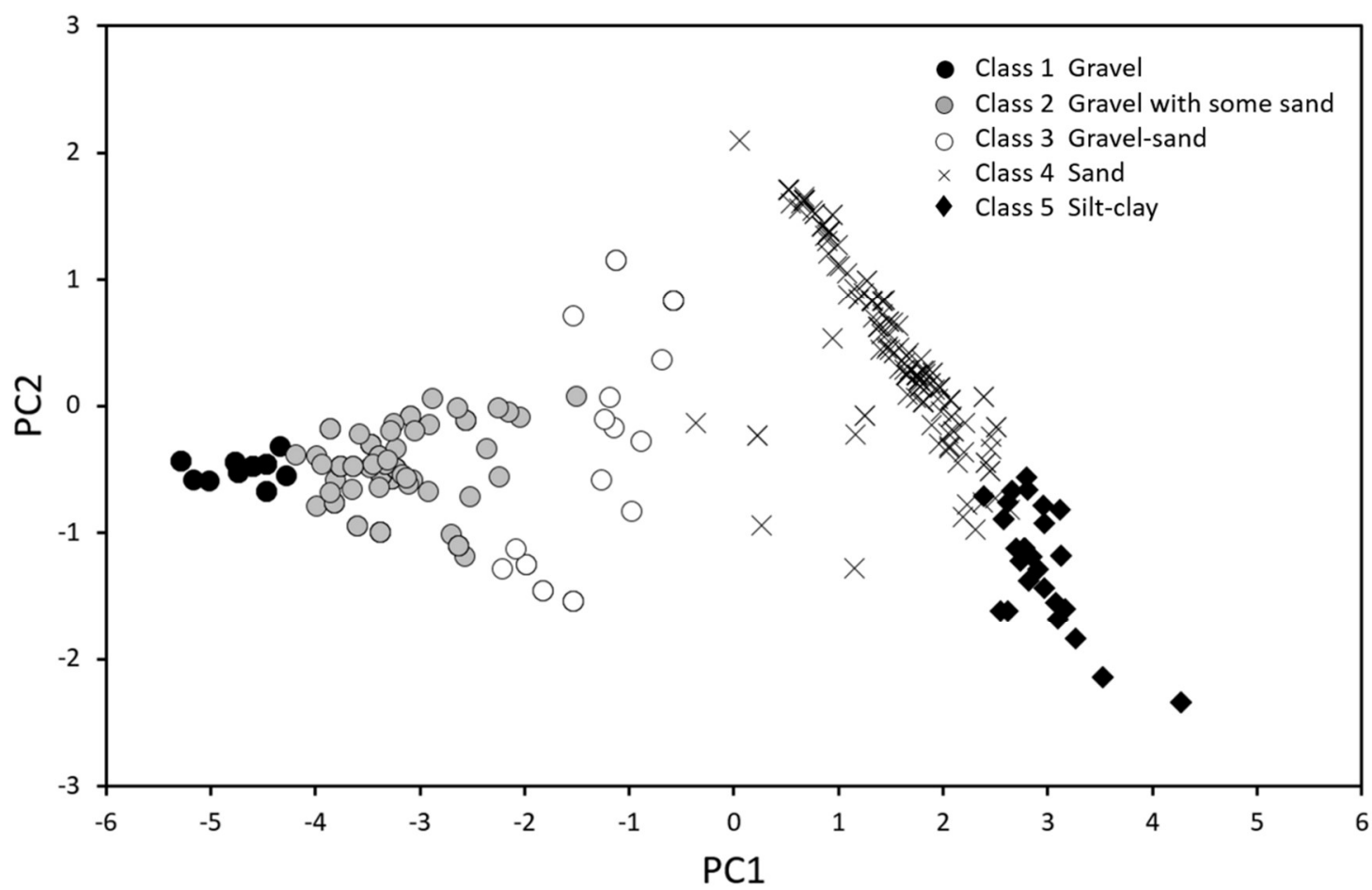

15 Figure 2: Sample scores of the 350 depth interval sediments on principal component 1 and 2. Each 16 sample is coded according to its class following Hierarchical Cluster Analysis of the same data set. The 17 key briefly characterises each sediment class and more detailed information is provided in Table 4 . 

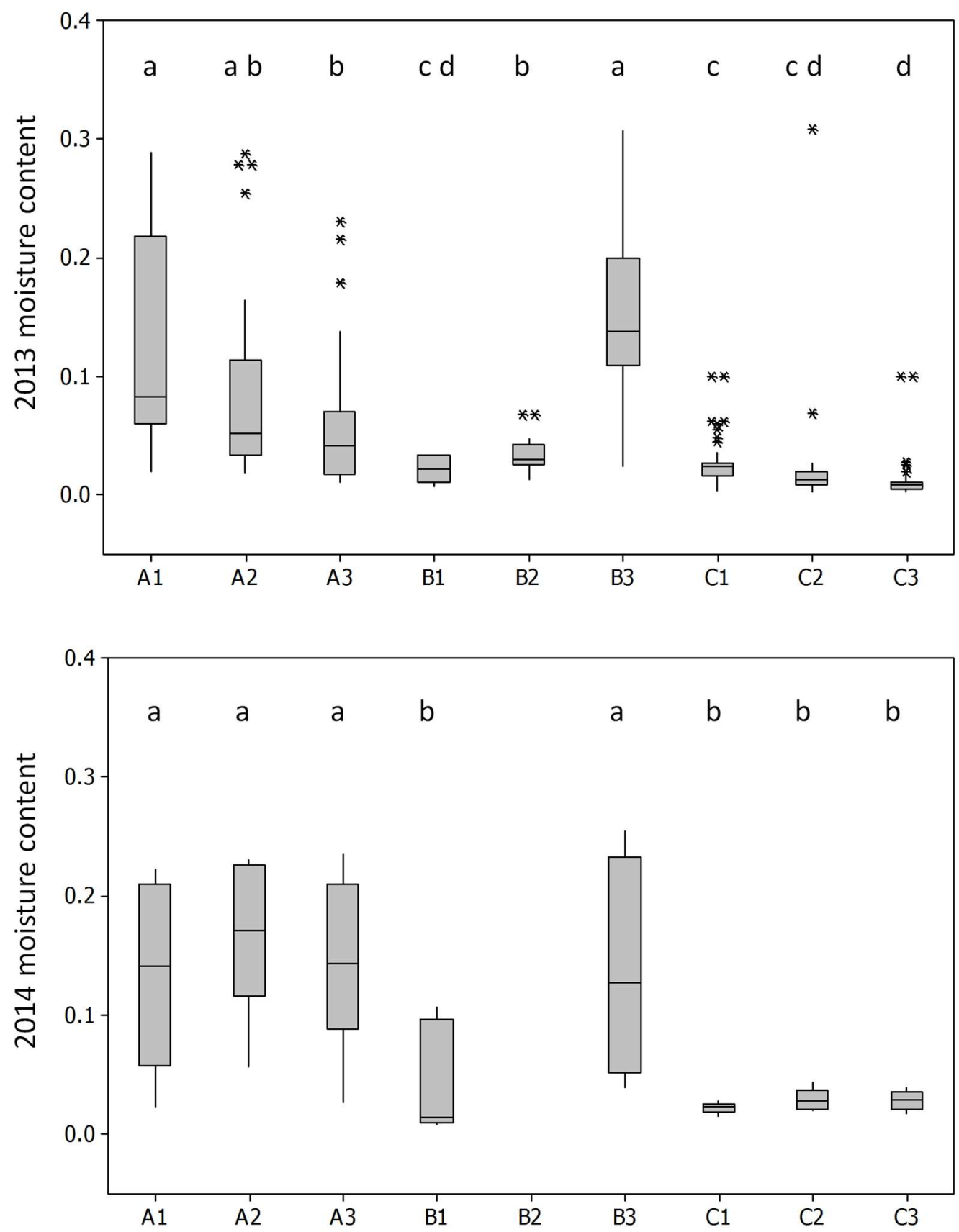

site

20 Figure 3: Box and whisker plots of proportional sediment moisture content by weight at the nine studied sites in 2013 (upper graph) and at eight sites in 2014 (lower graph). In each graph the letters a, b, c and d identify statistically significant groups of sites according to Kruskal Wallis tests with multiple pairwise comparisons using Dunn's procedure. The boxes are defined by the upper and lower quartiles of the observations and also show the median. The whiskers extend to the largest (positive or negative) observation within 1.5 times the interquartile range beyond the upper or lower quartile, respectively. Outliers are all observations that fall outside of this range. 


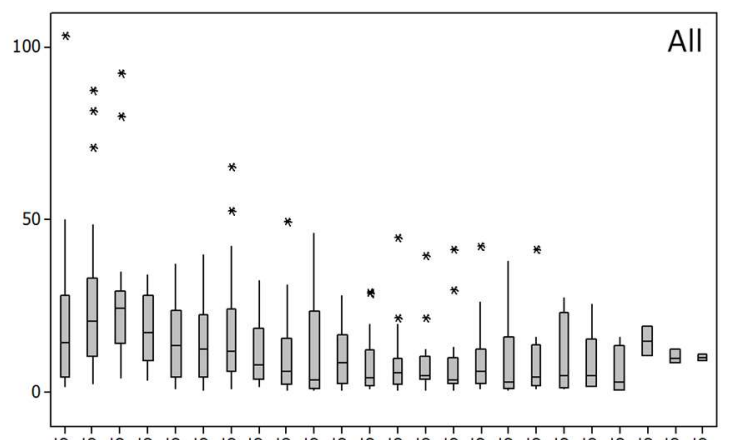

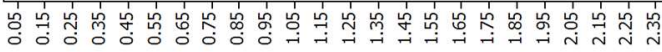
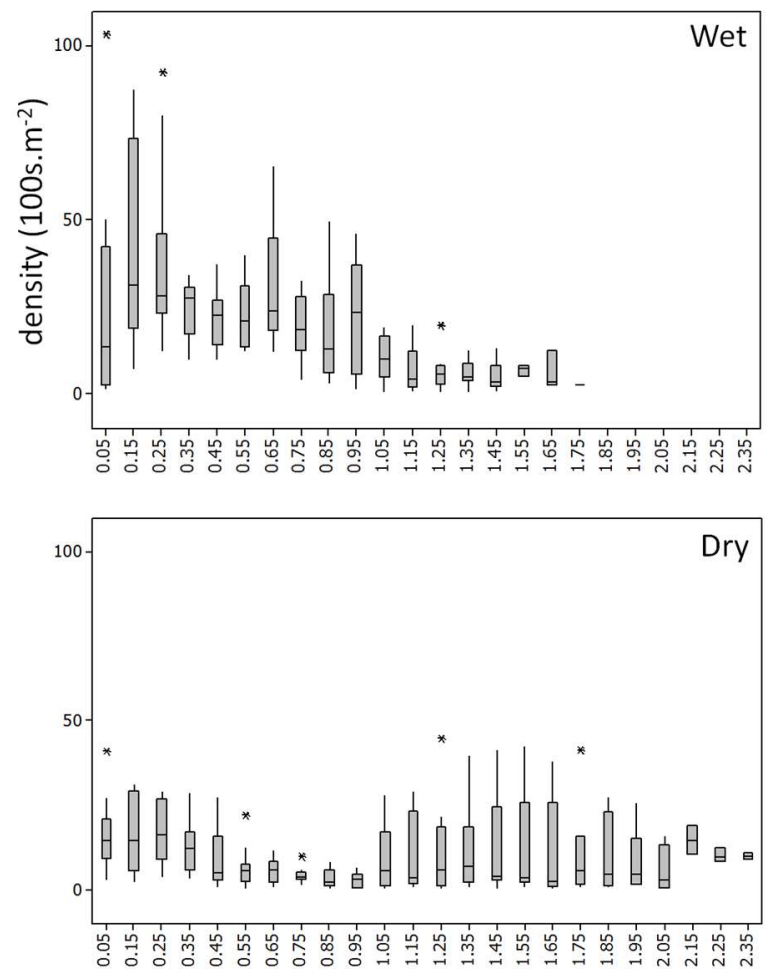

interval mid-point depth $(\mathrm{m})$
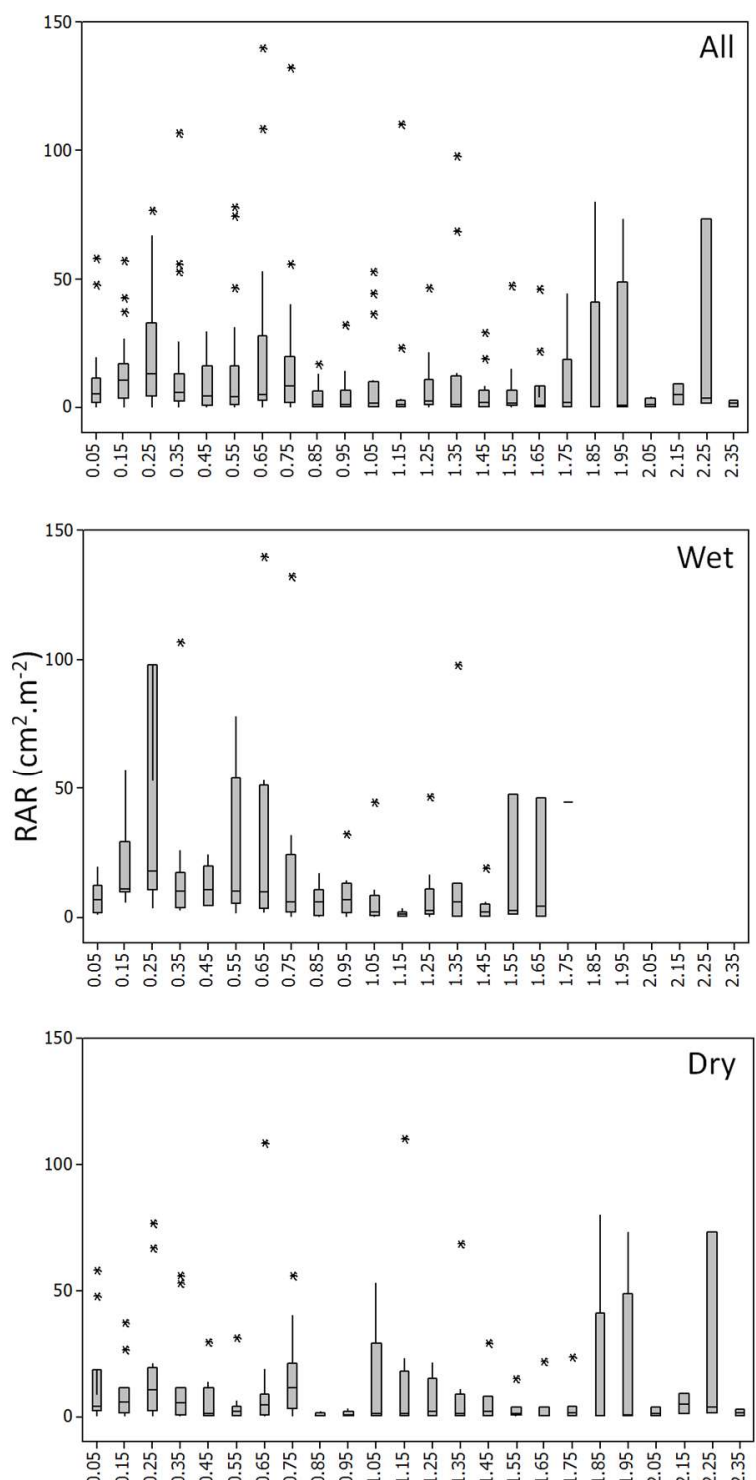

interval mid-point depth (m)

Figure 4: Box and Whisker plots of root density (left) and RAR (right) are plotted for each $10 \mathrm{~cm}$ depth interval for the entire data set (upper graphs), wet sites (middle graphs) and dry sites (lower graphs). The boxes are defined by the upper and lower quartiles of the observations and also show the median. The whiskers extend to the largest (positive or negative) observation within 1.5 times the interquartile range beyond the upper or lower quartile, respectively. Outliers are all observations that fall outside of this range. 

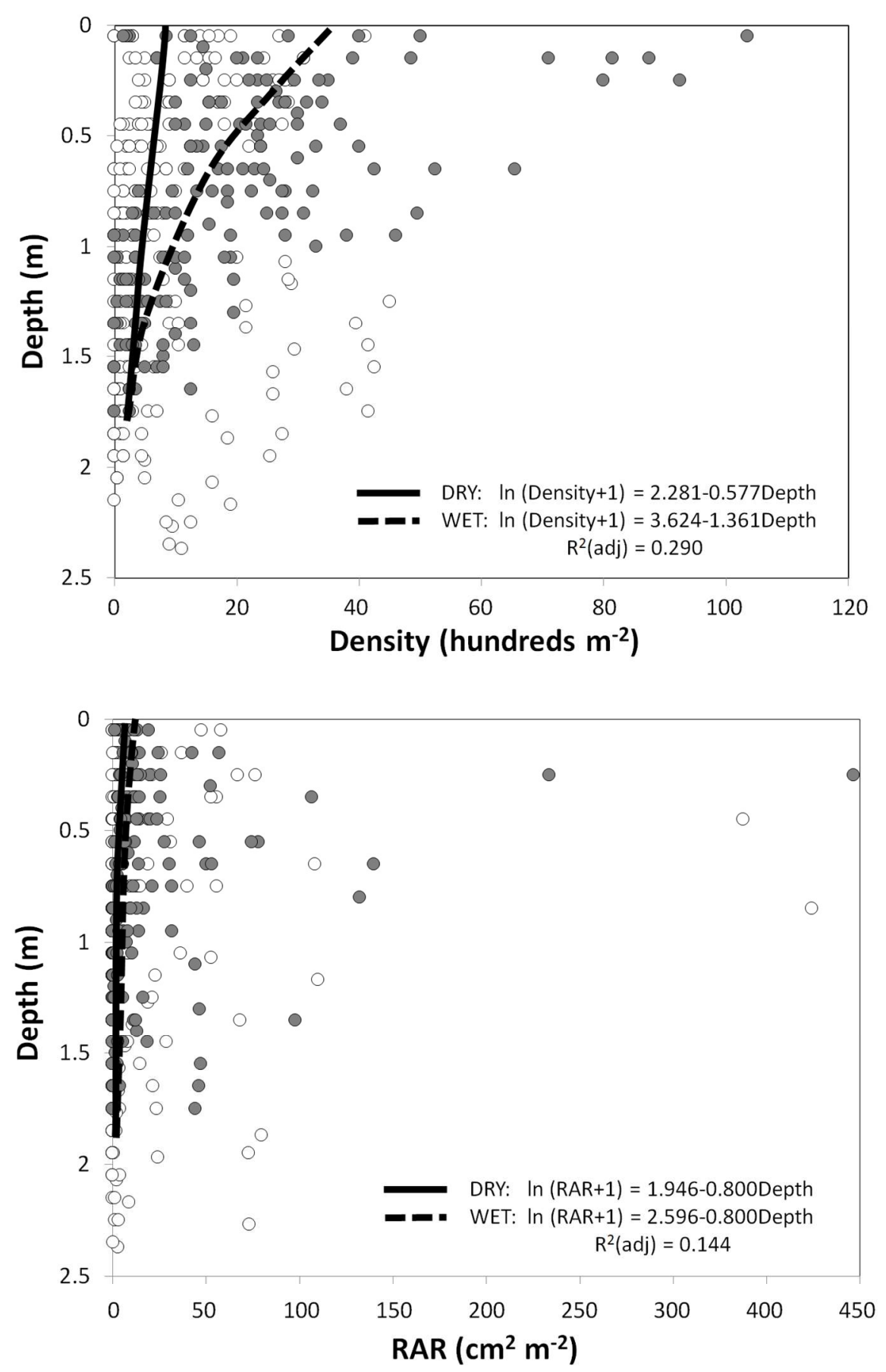

38 Figure 5: Distribution of root density (above) and RAR with depth in the bank profile. Statistically 39 significant regression curves with the highest coefficient of determinations for each variable (see 40 Table 6) are plotted separately for the groups of wet and dry sites. 